\title{
Polymorphism of eps loci involved in exopolysaccharide synthesis of Streptococcus thermophilus
}

\author{
Florence Charron-Bourgoin*, Arnaud Pluvinet, \\ Catherine MOREL, Gérard GUÉDON, Bernard DECARIS \\ Laboratoire de Génétique et Microbiologie, UA INRA 952, Université Henri Poincaré Nancy 1, \\ Faculté des Sciences, BP 239, 54506 Vandœuvre-lès-Nancy, France
}

\begin{abstract}
The nucleotide sequence of two ORFs and five copies of three insertion sequences (IS) types belonging to the eps locus of Streptococcus thermophilus CNRZ368 involved in exopolysaccharide synthesis are almost identical to ISs and ORFs sequences from Lactococcus lactis. Furthermore, sequence comparison of eps loci of three $S$. thermophilus strains and hybridization of probes isolated from the S. thermophilus CNRZ368 eps locus with DNA of 17 S. thermophilus strains revealed a very high polymorphism. A small constant region is detected in all the strains whereas a large region is extremely variable. The 17 tested strains could be arranged in six groups according to the presence or absence of a hybridization signal with the different probes tested. A phylogenetic analysis indicated that the ropy NST2280 strain and the non-ropy IP6757 strain are very closely related strains but possess different eps loci. The eps locus of IP6757 could result from sequence replacement in an IP6757 ancestor. Sequence comparison of different eps loci of $S$. thermophilus suggests that the high polymorphism of these loci largely results from sequence replacement following horizontal transfers.
\end{abstract}

exopolysaccharide / horizontal transfer / Lactococcus lactis / polymorphism / Streptococcus thermophilus

Résumé - Polymorphisme des loci eps impliqués dans la synthèse d'exopolysaccharides chez Streptococcus thermophilus. L'étude du locus eps chez S. thermophilus CNRZ368, impliqué dans la synthèse d'exopolysaccharides (EPS), a révélé plusieurs séquences presque identiques à des séquences de Lactococcus lactis ( 5 copies de 3 types d'IS et 2 ORF). Par ailleurs, la comparaison des séquences des loci eps de 3 souches de $S$. thermophilus ainsi que l'hybridation de sondes issues du locus eps de $S$. thermophilus CNRZ368 sur l'ADN de 17 souches de $S$. thermophilus ont révélé une petite région constante présente chez toutes les souches ainsi qu'une grande région extrêmement variable. Les 17 souches étudiées ont pu être rassemblées en 6 groupes présentant des structures similaires (présence ou non de séquences homologues aux régions testées). Une analyse phylogénétique

* Correspondence and reprints

Tel.: (33) 383912000 (extension 3506); fax: (33) 3839125 00;

e-mail: Florence.Bourgoin @ scbiol.u-nancy.fr 
de ces souches indique que $S$. thermophilus NST2280, une souche productrice d'EPS, et IP6757, une souche non productrice, sont très proches phylogénétiquement mais possèdent des loci eps différents. Le locus eps d'IP6757 résulterait d'un remplacement de séquence qui se serait produit chez un ancêtre d'IP6757. La comparaison des séquences des différents loci eps de $S$. thermophilus suggère que des séquences ont été remplacées par des séquences non homologues acquises lors de transferts horizontaux intra- et interspécifiques.

exopolysaccharide / Lactococcus lactis / polymorphisme / Streptococcus thermophilus / transfert horizontal

\section{INTRODUCTION}

Cocultures of Streptococcus thermophilus and various lactic acid bacteria including Lactococcus lactis are used as starters in the production of some cheeses.

Sequence comparison and insertion sequence (IS) distribution showed that horizontal transfers of five IS types have occurred spontaneously between $S$. thermophilus and L. lactis, probably during cheese manufacture [1, 2, 6-8]. Furthermore, the citP genes from L. lactis and Leuconostoc lactis which encode citrate permease share $99.2 \%$ identity, suggesting a recent horizontal transfer between these species [13]. Moreover, the nucleotide sequences of the putative $h s d S$ genes of the pCI65st plasmid of $S$. thermophilus and the pIL7 plasmid of L. lactis encoding the specificity subunit of a type I restriction-modification system share 94\% identity [9]. Many horizontal transfers of IS and other genes have probably occurred between various lactic acid bacteria species used in the dairy industry, contributing to their genetic polymorphism [8].

\section{INVOLVEMENT}

OF HORIZONTAL TRANSFERS IN THE CHIMERIC STRUCTURE OF THE EPS LOCUS OF S. THERMOPHILUS CNRZ368

A $32.5 \mathrm{~kb}$ variable region of the $S$. thermophilus CNRZ368 chromosome, the eps locus, contains seven complete or truncated ISs and 25 ORFs or pseudo-ORFs (Fig. 1). The putative products of 17 ORFs, named epsA to eps $W$, are related to proteins involved in the synthesis of exopolysaccharides or capsular polysaccharides in various bacteria.

This eps locus includes a $15.3 \mathrm{~kb}$ region which contains two $\alpha$ ISS 1 copies, one $\alpha \beta I S S 1$ copy and two of the four IS981 copies present in the $S$. thermophilus CNRZ368 genome. These ISs were probably acquired by horizontal transfers from L. lactis $[7,8]$. This $15.3 \mathrm{~kb}$ region also contains $\operatorname{orf} B$ and eps $L$ which share $97.6 \%$ identity with orfY and epsL of the plasmidic eps locus of L. lactis NIZOB40 [12]. Furthermore, most of the probes isolated from this $15.3 \mathrm{~kb}$ region hybridize with closely related sequences of $L$. lactis strains (Fig. 1). This suggests that a large part of this eps locus has been transferred from $L$. lactis to $S$. thermophilus.

The 126-nt 5' end of epsL of $S$. thermophilus CNRZ368 shares only 55\% with epsL of L. lactis NIZOB40 whereas the other region of epsL is almost identical. Therefore, an illegitimate recombination between distantly related sequences could be involved in the integration of a lactococcal sequence into the $S$. thermophilus CNRZ368 chromosome. IS981SC could correspond to the other end of the $15.3 \mathrm{~kb}$ transferred region and could be involved in the integration. This transferred region probably transported four IS types and genes involved 


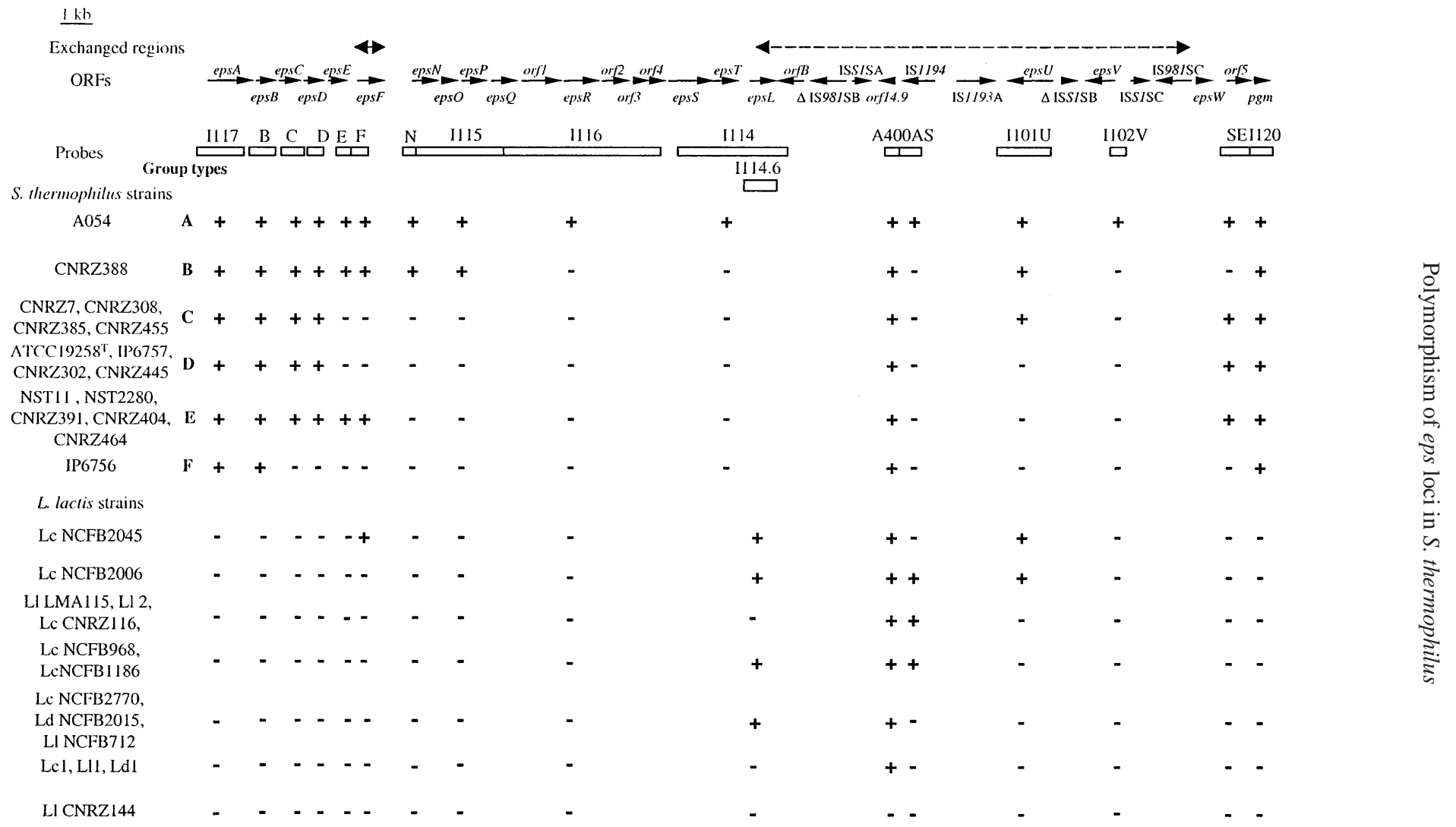

Figure 1. Map of the eps locus of S. thermophilus CNRZ368 and hybridization of probes with DNA of S. thermophilus or L. lactis strains. Arrows indicate localization and orientation of the putative genes or pseudo-genes. $\triangle \mathrm{IS}$ corresponds to a truncated IS. All the ORFs indicated as eps encode putative proteins related to proteins involved in polysaccharide synthesis. The probes shown by white boxes were hybridized on EcoRI restriction patterns of genomic DNA from $S$. thermophilus or L. lactis strains. 
in exopolysaccharide synthesis and was subject to rearrangements after its integration.

Furthermore, a specific probe of epsF isolated from the eps locus of $S$. thermophilus CNRZ368 hybridized with Lactococcus DNAs (Fig. 1), suggesting that eps $F$ would also be exchanged between $S$. thermophilus and L. lactis.

The $\mathrm{G}+\mathrm{C}$ content of the eps locus of $S$. thermophilus CNRZ368 is highly heterogeneous ( 26 to $42 \%$ ) while the $\mathrm{G}+\mathrm{C}$ content of the $S$. thermophilus genome is $37.2-39.8 \%$ [4]. This suggests that some regions of this locus could be acquired by horizontal transfer from different origins, perhaps from other lactic acid bacteria used in cocultures.

Hybridization of various probes from the eps locus of $S$. thermophilus CNRZ368 on EcoRI restriction patterns of $17 \mathrm{~S}$. thermophilus strains revealed a very high polymorphism (Fig. 1). Several small regions are present in all the $S$. thermophilus strains tested while the other regions are present in only some strains or are replaced by sequences which do not hybridize to the specific probes of the CNRZ368 eps locus. These hybridization results also showed that the various strains tested could be arranged in six groups, named $\mathrm{A}$ to $\mathrm{F}$, according to the presence or absence of a hybridization signal with the different probes tested (Fig. 1).

Sequence comparison of the eps locus from S. thermophilus CNRZ368, Sfi6 [10] and NCFB2393 [5] revealed almost identical regions, epsABCDEF and orf14.9 in Sfi6 and epsABCD in NCFB2393 (Fig. 2). However, the nature and number of genes involved in exopolysaccharide synthesis present in variable regions are very different among the strains. Generally, specific genes of a strain are unrelated or very distant from genes of other strains. Sequences related to epsE of CNRZ368 and Sfi6 were not identified in NCFB2393 (Fig. 2). In this strain, it is replaced by a completely different gene involved in exopolysaccharide synthesis. Furthermore, most of the other regions of the eps locus of $S$. thermophilus CNRZ368 are replaced by unrelated sequences in Sfi6 (Fig. 2), suggesting that these sequences could have been acquired by horizontal transfer(s).

These results suggest that eps loci of $S$. thermophilus strains have undergone numerous rearrangements leading to chimeric loci. Some of the rearrangement points could be precisely located: $5 \mathrm{nt}$ in the 3' end of epsD, $26 \mathrm{nt}$ from the 3' end of epsF and $8 \mathrm{nt}$ in the 3 ' end of orfl4.9 (Fig. 2).

\section{COMPARISON OF EPS LOCI FROM S. THERMOPHILUS NST2280 AND IP6757 STRAINS}

Phylogenetic relationships between the various $S$. thermophilus strains tested have been determined by hybridization of 12 specific probes of other variable regions, IS and genes encoding rRNA (Fig. 3). Hybridization patterns of the various strains showed a high polymorphism. However, hybridization patterns of NST2280 and IP6757 are almost identical, indicating that these strains are very closely related. However, the ropy strain NST2280 possesses a type E eps locus while the non-ropy strain IP6757 possesses a type D eps locus (Fig. 1). The phylogenetic analysis suggests that a common ancestor of a group of six strains, including NST2280 and IP6757, possessed a type E eps locus. This suggests that an IP6757 ancestor acquired a new eps locus type by sequence replacement following horizontal transfer while the other strains kept the ancestral eps locus.

The restriction map of the NST2280 eps locus is identical to that of Sfi6 deduced from its sequence [10] (data not shown). Furthermore, two PCR products were obtained in NST2280 by using primers located in the specific sequence of Sfi6 eps locus (in epsH and epsI, and in epsL and eps $M$ ). These products have the same size as in Sfi6 (data not shown). Therefore, the 
S. thermophilus CNRZ368

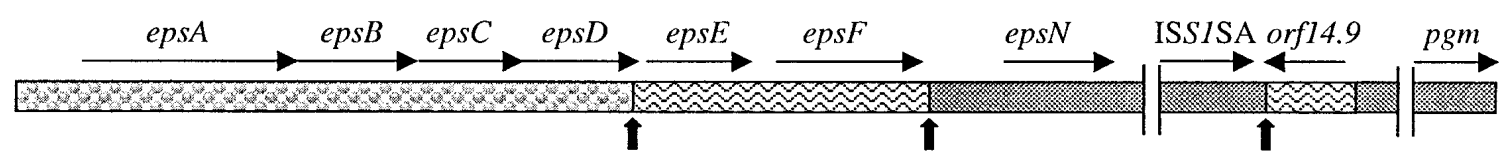

S. thermophilus Sfi6

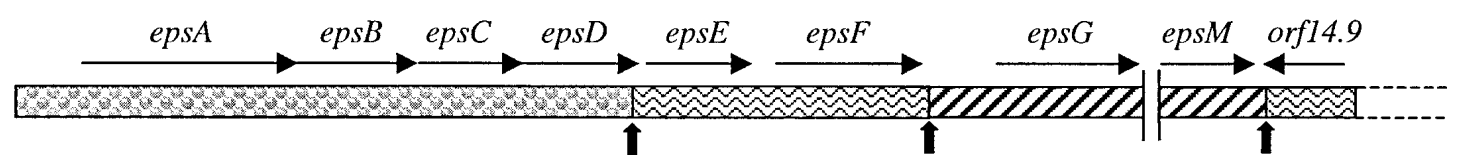

S. thermophilus NCFB2393

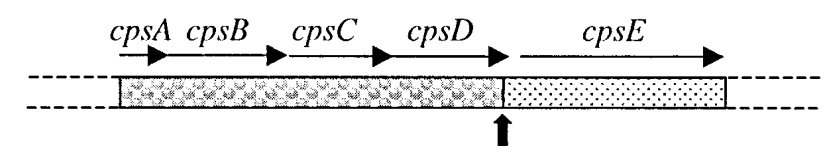

S. thermophilus IP6757

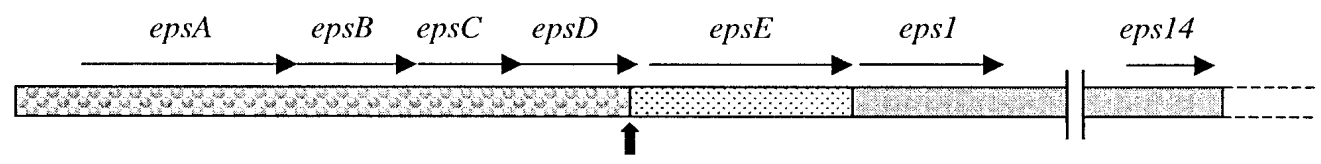

Figure 2. Comparison of the eps loci from S. thermophilus strains. Closely related nucleotide sequences (more than $90 \%$ identity) are shown by the same symbols. Black arrows indicate localization of rearrangement points. Partially sequenced genes or loci are shown by broken lines. 


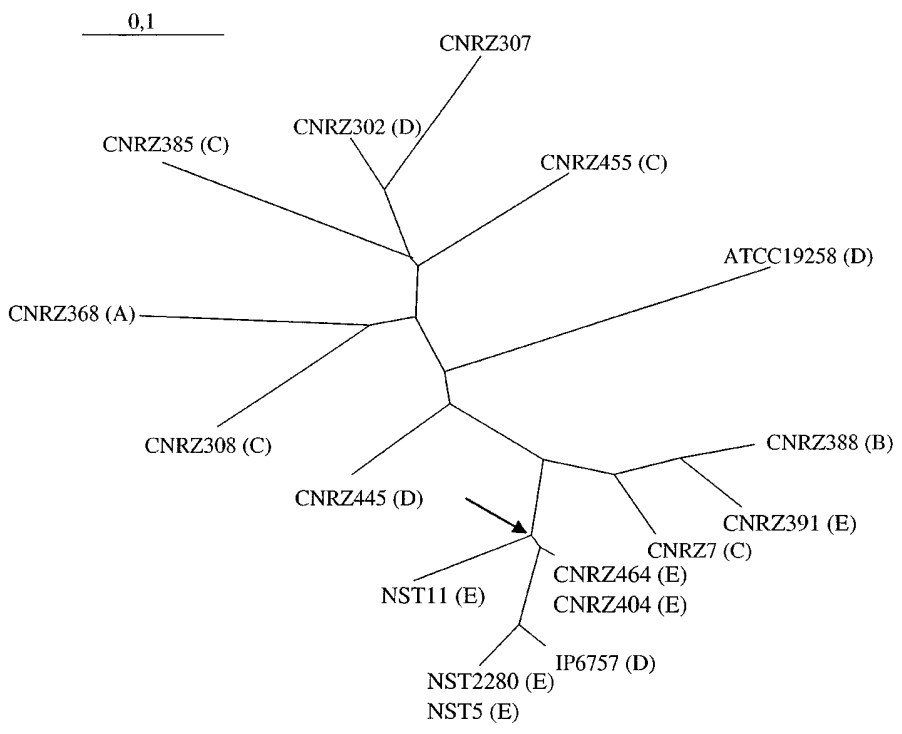

Figure 3. Dendrogram of $S$. thermophilus strains. 12 specific probes of $r r n$ loci, IS1191, IS1193 and variable loci were hybridized on DNAs digested by various restriction endonucleases. These hybridization patterns were used to produce a dendrogram by the neighbor-joining method using PAUP program [11]. Arrow indicates the common ancestor of the group of six strains which possess a type E eps locus except IP6757.

NST2280 eps locus is identical or very closely related to the eps locus of the ropy strain Sfi6.

The sequenced epsABCD region of the IP6757 eps locus is identical to that of Sfi6 (Fig. 2). This region is followed by epsE which shares $95 \%$ identity with cpsE of NCFB2393 and by a region containing 14 ORFs or pseudo-ORFs, named epsl to eps14. These ORFs are unrelated to those of CNRZ368, Sfi6 and therefore of NST2280. However, the putative products of these ORFs share significant similarities with proteins involved in polysaccharide synthesis of various bacteria. This sequence comparison also showed a rearrangement point at $5 \mathrm{nt}$ in the 3' end of epsD (Fig. 2).

Furthermore, hybridization of various probes from the eps locus of $S$. thermophilus IP6757 on EcoRI restriction patterns of $17 \mathrm{~S}$. thermophilus strains revealed a small constant region, the same as identified by hybridization of probes isolated from the CNRZ368 eps locus, and a large variable region which hybridizes only with IP6757 DNA (Fig. 4). Sequences related to this region are not present in NST2280 nor in the other strains of the D group previously defined. This D group should be divided into at least two groups, D (IP6757) and D' (ATCC19258, CNRZ302 et CNRZ445).

The $\mathrm{G}+\mathrm{C}$ content of the eps locus of S. thermophilus IP6757 is highly variable (20 to $43 \%$ ). Particularly, the $\mathrm{G}+\mathrm{C}$ content of the large eps2-eps 14 region which is detected only in the IP6757 strain is 30\% whereas the $\mathrm{G}+\mathrm{C}$ content of the $S$. thermophilus genome is $37.2-39.8 \%$ [4]. This suggests that this region could be acquired by horizontal transfer from different origins, perhaps from other lactic acid bacteria used in cocultures. 


\section{S. thermophilus} IP6757

Probes

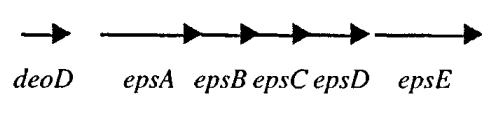
$\longrightarrow$
epsl eps 2 eps 3

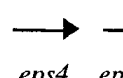

eps4 eps5 eps

eps 7 eps 8 eps 9

$\longrightarrow$

$\longrightarrow \longrightarrow$

eps1leps12 eps13 eps14

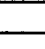

1

$1166 \quad 1165 \quad 1167$

L

168

I170

I169

Group Types

D

$+$

$+$

A, B, C, D', E, F

$+$

$+$

Figure 4. Map of the partially sequenced eps locus of S. thermophilus IP6757 and hybridization of probes with DNA of S. thermophilus strains. Arrows indicate localization and orientation of the putative genes or pseudo-genes. All the ORFs indicated as eps encode putative proteins related to proteins involved in polysaccharide synthesis. The probes shown by white boxes were hybridized on EcoRI restriction patterns of genomic DNA from $S$. thermophilus strains. A: CNRZ368, A054; B: CNRZ388; C: CNRZ7, CNRZ308, CNRZ385, CNRZ455; D: IP6757; D': ATCC19258, CNRZ302, CNRZ445; E: NST2280, A: CNRZ368, A054; B: CNRZ388; C: CNRZ7, CNRZ31 
These results show that the eps locus of S. thermophilus IP6757 contains several regions from different origins. The eps $A B C D$ region was inherited from its last common ancestor with NST2280 while the other regions were acquired by horizontal transfer(s).

\section{CONCLUSION}

These results indicate that eps loci of $S$. thermophilus have a chimeric structure resulting from recombination between unrelated or distantly related sequences acquired by spontaneous intra- and interspecific transfers. One of the mechanisms involved in these horizontal transfers could be conjugation since an integrative, potentially conjugative element (ICE) was found in $S$. thermophilus [3] and numerous conjugative elements were identified in L. lactis.

\section{REFERENCES}

[1] Bourgoin F., Guédon G., Pébay M., Roussel Y. Panis C., Decaris B., Characterization of a mosaic ISS1 element and evidence for the recent horizontal transfer of two different types of ISS between Streptococcus thermophilus and Lactococcus lactis, Gene 178 (1996) 15-23.

[2] Bourgoin F., Guédon G., Gintz B., Decaris B., Characterization of a novel insertion sequence, IS1194, in Streptococcus thermophilus, Plasmid 40 (1998) 44-49.

[3] Burrus V., Roussel Y., Decaris B., Guédon G., Characterization of a novel integrative element, ICESt 1 , in the lactic acid bacteria Streptococcus thermophilus, Appl. Environ. Microbiol. 66 (2000) 1749-1753.
[4] Farrow J.A.E., Collins M.D., DNA base composition, DNA-DNA homology and long chain fatty acid studies on Streptococcus thermophilus and Streptococcus salivarius, J. Gen. Microbiol. 130 (1984) 357-362.

[5] Griffin A.M., Morris V.J., Gasson M.J., The $c p s$ $A B C D E$ genes involved in polysaccharide production in Streptococcus salivarius ssp. ther mophilus NCFB2393, Gene 183 (1996) 23-27.

[6] Guédon G., Bourgoin F., Pébay M., Roussel Y., Colmin C., Simonet J.M., Decaris B., Characterization and distribution of two insertion sequences, IS1191 and iso-IS981, in Streptococcus thermophilus: does intergeneric transfer of ISs occur in lactic acid bacteria co-cultures? Mol. Microbiol. 16 (1995) 69-78.

[7] Guédon G., Bourgoin F., Decaris B., Does gene horizontal transfer occur in lactic acid bacteria co-cultures?, Lait 78 (1998) 53-58.

[8] Guédon G., Bourgoin F., Burrus V., Pluvinet A., Decaris B., Implication of horizontal transfers in genetic polymorphism of lactic acid bacteria, Sci. Aliments 20 (2000) 85-95.

[9] O'Sullivan T., van Sinderen D., Fitzgerald G., Structural and functional analysis of pCI65st, a $6.5 \mathrm{~kb}$ plasmid from Streptococcus thermophilus NDI-6, Microbiology 145 (1999) 127-134.

[10] Stingele F., Neeser J.R., Mollet B., Identification and characterization of the eps (exopolysaccharide) gene cluster from Streptococcus ther mophilus Sfi6, J. Bacteriol. 178 (1996) 1680-1690.

[11] Swofford D.L., PAUP: Phylogenetic analysis using parsimony, version 3.0s., Illinois Natura History Survey, Champaign, Illinois (1991).

[12] van Kranenburg R., Marugg J.D., van Swam I.I., Willem N.J., de Vos W.M., Molecular characterization of the plasmid-encoded eps gene cluster essential for exopolysaccharide biosynthesis in Lactococcus lactis, Mol. Microbiol. 24 (1997) 387-397.

[13] Vaughan E.E., David S., Harrington A., Daly C. Fitzgerald G.F., de Vos W.M., Characterization of a plasmid-encoded citrate permease (citP) gene from Leuconostoc species reveals high sequence conservation with the Lactococcus lactis citP gene, Appl. Environ. Microbiol. 61 (1995) 3172-3176.

To access this journal online:

www.edpsciences.org 